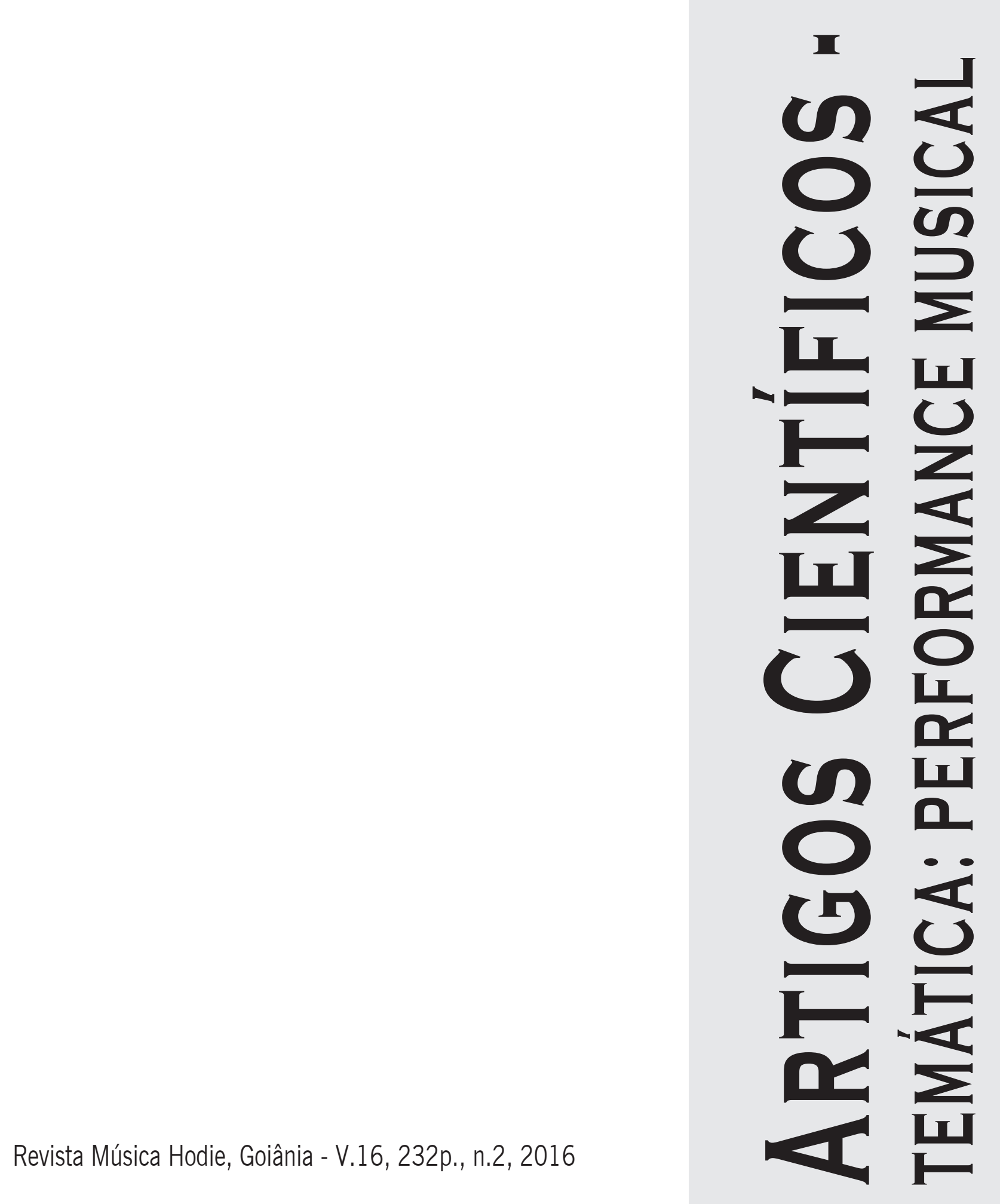




\title{
A percussão típica brasileira na obra Variações Rítmicas Opus 15 de Marlos Nobre
}

\author{
Rodolfo Vilaggio Arilho (Universidade Estadual de Campinas, Campinas, SP, Brasil) \\ rodolfo.arilho@gmail.com
}

Fernando Augusto de Almeida Hashimoto (Universidade Estadual de Campinas, Campinas, SP, Brasil) ferhash@iar.unicamp.br

\begin{abstract}
Resumo: Este artigo aborda os instrumentos de percussão tipicamente brasileiros utilizados por Marlos Nobre em sua obra Variações Rítmicas para piano e seis percussionistas, composta em 1963. Essa pode ser considerada a primeira peça de repercussão no cenário brasileiro para esta formação. Nobre mescla os instrumentos da percussão popular como cuíca aguda, chocalho de metal, afoxé, reco-reco, agogô, pandeiro, tamborim e três atabaques, com uma obra que tem características eruditas, dodecafônicas e seriais.

Palavras-chave: Instrumentos de percussão; Marlos Nobre; Variações Rítmicas; Percussão brasileira.
\end{abstract}

The typical brazilian percussion in Variações Rítmicas Opus 15 by Marlos Nobre

Abstract: This article discusses the typical Brazilian percussion instruments used by the Brazilian composer Marlos Nobre in his composition Variações Rítmicas for piano and six percussionists, written in 1963. This can be considered the first piece of repercussion in the Brazilian musical scenario for this kind of chamber music. The composer Marlos Nobre merges the popular percussion instruments such as small Brazilian 'cuíca', metal shaker, cabasa, rasper, agogo bells, Brazilian tambourine, Brazilian 'tamborim' and three 'atabaques', with a composition which has classical, twelve-tone and serial features.

Keywords: Percussion instruments; Marlos Nobre; Variações Rítmicas; Brazilian percussion.

La percusión típica brasileña en la obra Variações Rítmicas Opus 15 por Marlos Nobre

Resumen: Este estudio analiza los instrumentos de percusión típicamente brasileños utilizados por Marlos Nobre en su obra Variações Rítmicas para piano y seis percusionistas, compuesta en 1963. La obra puede ser considerada la primera pieza de repercusión en el escenario brasileño para esta formación. Nobre fusiona los instrumentos de percusión populares como cuica aguda, xocalho de metal, cabaza, guiro, cencerros, pandereta brasileña, tambor pequeño y tres tumbadoras, con una obra dodecafónica y serial.

Palabras clave: Instrumentos de percusión; Marlos Nobre; Variações Rítmicas; Percusión brasileña.

Marlos Nobre, compositor e maestro brasileiro, nasceu em Recife, Pernambuco, em 18 de fevereiro de 1939. Iniciou seus estudos musicais ainda jovem, com aproximadamente cinco anos de idade. Entre 1948 e 1959, estudou piano e teoria musical no Conservatório Pernambucano de Música, harmonia e contraponto com o Pe. Jaime Diniz entre 1956 e 1959. Em 1958, ganhou uma bolsa de estudos do Departamento de Documentação e Cultura do Recife e participou do I Curso Nacional de Música Sacra. Estudou composição com H.J. Koellreutter (1915-2005) e com Camargo Guarnieri (1907-1993). Em 1963, no Instituto Torcuato di Tella, em Buenos Aires, Argentina, estudou com Alberto Ginastera (1916-1983), Olivier Messiaen (1908-1992), Aaron Copland (1900-1990), Luigi Dallapiccola (1904-1975) e Bruno Maderna (1920-1973).

Nobre pode ser considerado um dos grandes nomes da composição a partir da segunda metade do século XX, sendo reconhecido nacional e internacionalmente. Segundo o historiador, musicólogo, escritor e diplomata brasileiro Vasco Mariz (1994, p. 372.), "Marlos Nobre é, de longe, o compositor brasileiro contemporâneo mais premiado, mais gravado, mais editado". Suas obras representam o produto de um compositor original e criativo.

Nobre teve uma rígida formação musical desde cedo. Ele acompanhava seu pai, um violonista amador, em saraus onde tinha a oportunidade de ouvir os mais variados 
gêneros musicais da época. Nasceu e viveu sua infância em Recife, considerado, no período em questão, um dos centros culturais mais importantes do país, tendo contato direto com a música popular e folclórica brasileira. Esses fatos podem ter sido fundamentais para caracterizar a música de Nobre e sua diversidade composicional, que mescla a música brasileira, a música erudita européia e a música erudita contemporânea. Ao somar suas lembranças musicais da infância, como a música popular vivenciada de perto nas ruas do Recife, com estudo das músicas dos grandes mestres da música erudita nacional e internacional, Nobre mostra-se um compositor que busca criar uma linguagem própria em suas composições, mesclando a música de seu passado com as novas tendências da música contemporânea.

Nobre inicia seu processo de composição através da organização coerente de uma ideia musical que surge, aparentemente, de forma espontânea em seu subconsciente. Para o compositor, uma obra tem que ser produzida de forma simples. Variações e repetições são de fundamental importância nas obras de Nobre, que criava uma, duas ou várias obras partindo do desenvolvimento de um único e 'simples' motivo.

Podemos dividir a produção composicional de Nobre em cinco períodos. O Primeiro Período, que abrange os anos de 1959 até 1963, é marcado pela influência de Villa-Lobos e, principalmente, de Ernesto Nazareth. Essa influência é comprovada pela presença de elementos característicos da música folclórica e popular. Algumas de suas primeiras composições utilizam um sistema tonal. Com o tempo, Nobre inclui elementos atonais, politonais e até seriais. São características desse período obras como Concertino para piano e orquestra de cordas opus 1 (1959), Homenagem a Ernesto Nazareth opus 1 a (1959), Nazarethiana opus 2 (1961) e Divertimento para piano e orquestra opus 14 entre outras.

O Segundo Período começa em 1963 e estende-se até 1968. Essa fase inicia-se com sua ida a Buenos Aires, onde, no Instituto Torcuato Di Terra, foi estudar como bolsista. Foi onde passou a estudar com Alberto Ginestera (1916-1983), Riccardo Malipiero (1914-2003) e outros, aumentando seu contato e o desenvolvimento da linguagem dodecafônica e mesclando-a ainda com o folclore brasileiro e com as raízes nacionais.

Nobre está sempre ligado à riqueza rítmica da música brasileira e, para esse segundo período, podemos destacar como seu início a obra Variações Rítmicas Opus 15 (1963) para piano e percussão tipicamente brasileira, uma obra dodecafônica e serial. Também temos Ukrinmakrinrin opus 17 (1964) para soprano, sopros e piano, uma obra serial que, em sua segunda parte, é composta com processos aleatórios.

O Terceiro Período, que vai de 1969 até 1977, é caracterizado pela mescla dos processos composicionais aprendidos e utilizados até este momento, como o serialismo, a música aleatória, procedimentos politonais e o atonalismo.

Nesse Terceiro Período, podemos destacar o Concerto Breve opus 33 (1969) para piano e orquestra, Ludus Instrumentalis opus 34 (1969) para orquestra de câmara, Mosaico opus 36 (1970) para orquestra, Sonâncias I opus 37 (1972) para piano e percussão, O Canto Multiplicado opus 38 (1972) para soprano e piano e In Memoriam opus 39 (1973) para orquestra, entre outras. Nos anos de 1978 e 1979, Nobre não compôs nenhuma obra.

O Quarto Período estende-se, entre os anos de 1980 a 1989. Esse período, caracteriza-se pela utilização dos elementos rítmicos do folclore nordestino brasileiro, com uma harmonia densa, mas que não abandona os elementos tonais, fazendo uso da escrita contrapontística. Em sua estrutura, é mantido o desenvolvimento das idéias iniciais da obra. Para esse período, podemos destacar: Sonâncias III opus 49 (1980) para dois pianos e dois percussionistas, Yanomani opus 48 (1980) para coro misto, tenor e violão e Sonâncias II (1980) para piano e percussão. 
O Quinto Período, que também é o último deles, começa em 1989 e vai até os dias atuais. Nesse período, Nobre utiliza-se de estruturas formais, combinando-as com elementos da música ocidental tonal e contemporânea. Nesse período, as obras em destaque são: Concertante do Imaginário opus 74 (1989) para piano e orquestra de cordas, Concerto Duplo opus 82 (1995) para dois violões e orquestra, Passacaglia opus 84 (1997) para orquestra, Concerto para percussão e orquestra opus 89 (2000), Kabbalah opus 96 (2004) e Frevo n. 2 opus 105 (2007).

\section{A obra Variações Rítmicas}

A obra Variações Rítmicas opus 15 (1963) inicia o Segundo Período de composições de Marlos Nobre. Foi dedicada ao compositor italiano Riccardo Malipiero, com quem estudou durante sua estada na Argentina, no Instituto Torcuato Di Terra. A obra traz a mescla entre o serialismo e os traços da rítmica brasileira, sendo composta para piano e percussão típica brasileira, incluindo cuíca aguda, chocalho de metal, afoxé, reco-reco, agogô, pandeiro, tamborim e três atabaques. Segundo Hashimoto (2003, p. 71), pode ser considerada a “primeira peça de repercussão no cenário brasileiro para esta formação”.

Variações Rítmicas teve sua estreia mundial em 1963, mesmo ano de sua composição, no Auditório do Museu de Artes Visuais em Buenos Aires, Argentina. Nesse concerto participaram o pianista Gerardo Gandini (1936-2013), o Conjunto Ritmos de Percussion de Buenos Aires e o maestro Armando Krieger (1940).

No Brasil, Variações Rítmicas teve sua estreia em 23 de novembro de 1973 no Teatro Municipal do Rio de Janeiro. A obra foi executada pelo Conjunto Música Nova do Rio de Janeiro, formado pelos percussionistas José Ribeiro, Orlando Trinca, José Santana, Antônio Almeida da Anunciação, Emílio Gama e Edgar Rocca, junto a pianista Maria da Penha, tendo como regente o próprio compositor Marlos Nobre (HASHIMOTO, 2003, p. 72).

Variações Rítmicas apresenta dez seções em movimento contínuo, começando com a apresentação do tema, seguido por oito variações e uma coda final, e tem duração de aproximadamente dez minutos. Para sua execução, são necessários um pianista e seis percussionistas. A obra começa com a apresentação do tema sendo exposto pelo piano e por todos os instrumentos de percussão num movimento que deve ter como característica uma 'forte e violenta' sonoridade, atributos apontados pelo compositor logo no início da obra. As variações que se seguem são desenvolvidas sobre a estrutura rítmica do tema até então apresentado.

A primeira variação é quase como uma continuação, uma imitação do tema. A segunda se faz um pouco mais calma, com um tempo mais livre, menos marcado, porém possui algumas poucas intervenções, como um contraste na dinâmica forte. Na terceira variação, volta o caráter mais rápido e sonoro. Na quarta, tem-se um leve scherzando. Na quinta, o tempo marcato segue com uma variação representada apenas pelo piano e pelo atabaque. A sexta apresenta, além do piano, todos os instrumentos de percussão num movimento rápido, sugerido por Nobre como quasi presto. A sétima variação tem o tempo bem calmo e livre, tendo, ao seu final, uma condução mais 'exaltada' e 'nervosa' do piano, que culmina na oitava e última variação, apresentada apenas pelos instrumentos de percussão.

A coda começa com uma cadência do piano, reconstruindo todo o material temático apresentado, enquanto a percussão vai entrando aos poucos e seguindo com um ritmo regular, ‘juntos começam um crescendo’ chegando a um final intenso e sonoro. 


\section{Os instrumentos típicos brasileiros}

A seguir, será apresentado um panorama dos instrumentos da percussão popular típica brasileira utilizados por Nobre em sua obra Variações Rítmicas opus 15.

\subsection{Cuíca}

Chamada de mpwita (em Angola), a cuíca é conhecida pelo nome de kpwita na língua Kimbundo. É conhecida também por puíta, tambos-onça ou tambor-onça, omelê, socador, roncador, porca ou onça e ronca. Esse instrumento tem formato de um pequeno tambor com a pele fixada a uma haste de madeira interna que friccionada com um pano molhado reproduz um som parecido com um ruído de um porco. Anteriormente, essa haste era externa.

Sambista, ritmista, passista, cantor e compositor paulistano do bairro do Bom Retiro, Osvaldo Barros, o Osvaldinho da Cuíca (1940), um dos nomes mais conhecidos no instrumento, afirma que, no início da década de 1920, a cuíca já estava incorporada ao samba, mas com um pequeno detalhe no instrumento: a vareta era tocada pelo lado de fora e não fazia tantas notas.

No Rio de Janeiro, entre os cuiqueiros, nome dado aos tocadores de cuíca, uma das maiores referências nesse instrumento é Zeca da Cuíca (1934), que se destacou ainda muito jovem, atuando nas escolas de samba e desfiles de carnaval. Contudo, foi atuando em estúdios de gravação que ele se tornou um dos grandes nomes da cuíca no Brasil, participando de várias gravações com inúmeros artistas dos mais variados gêneros musicais.

Maestro e compositor de renome internacional, considerado o expoente máximo da música do Modernismo no Brasil, Heitor Villa-Lobos (1887-1959) pode ter sido um dos primeiros, senão o primeiro compositor brasileiro, a utilizar a cuíca na música erudita brasileira. Villa-Lobos pode ter criado uma nova fase na música brasileira, buscando uma sonoridade que representasse o nacional e a liberdade de expressão. Isso foi consequência, provavelmente, da forte influência da cultura popular em sua adolescência, durante a qual teve contato com grupos de chorões (músicos integrantes do choro), e de seu interesse pela música do interior do Brasil (CUNHA, 2004, p. 16).

Essa influência da música popular faz com que, para Villa-Lobos, o ritmo se torne o ponto essencial da técnica para construção musical, formando sequências de ostinato que se sucedem e/ou se sobrepõem. Em Nonetto (1923), essa característica é visivelmente notada. Nonetto foi escrita para um conjunto inusitado: flauta, oboé, clarineta, sax (alto e tenor) fagote, piano, harpa, celesta, percussão e core misto. Ao que tudo indica, essa foi a primeira obra orquestral a utilizar a cuíca, outros instrumentos de percussão utilizados foram: reco-reco, pandeiro, chocalhos. Villa-Lobos também fez uso da cuíca em sua série de Choros, sua audição faz-se perceptível nos Choros 6 (1926), Choros 8 (1925), Choros 10 (1926) e Choros 12 (1929).

Outro grande compositor da música erudita brasileira foi Camargo Guarnieri (19071993). Guarnieri tem em seu repertório aproximadamente 700 obras compostas e é, provavelmente, o segundo compositor erudito brasileiro mais tocado no mundo, sendo superado apenas por Villa-Lobos. Aos 85 anos, pouco antes de seu falecimento, recebeu o prêmio 'Gabriela Mistral', pela OEA (Washington), com o título de 'Maior Compositor Contemporâneo das Três Américas'. Guarnieri utilizou a cuíca em seu Concerto $n^{o} 1$ para violino e orquestra (1940). 
Dentro da música erudita brasileira, a cuíca passou a ser utilizada não só nas orquestras, também nas obras compostas para grupos de percussão erudita. Dentre essas obras, podemos destacar: Guaraqueçaba: Antes e Depois (1976), de Brenno Blauth (1931-1993); Concertante (1969/70), de Sergio Vasconcelos Correa (1934); Três Estudos para Percussão (1966), de Osvaldo Lacerda (1927-2011); e Variações Rítmicas (1963), de Marlos Nobre (1939).

\subsection{Chocalho}

O Chocalho consiste num cilindro oco que pode ser de madeira, de metal, de plástico ou de outro material. Em seu interior, são colocados objetos como conchinhas, missangas, sementes, areia, etc. O som é produzido agitando-se o instrumento, de modo que os objetos no seu interior se choquem contra suas paredes internas.

Nas obras escritas pelos compositores brasileiros mais conhecidos, também são utilizados instrumentos como o chocalho. Villa-Lobos (1887-1959) é um exemplo disso, ele faz uso de chocalhos (metal, madeira, maracas e outros) em obras como: Amazonas (1917); Bachiana no 2 (1930), Choros no 8 (1925), Choros no 10 (1926), Fantasia em Três Movimentos (1958), Gênesis (1954), Nonetto (1923) entre outras.

Mozart Camargo Guarnieri (1907-1993) também fez uso dos chocalhos em algumas de suas obras, como em Três Danças para Orquestra (1946) e em Suíte Vila Rica para Orquestra (1958). Na obra Sinfonia dos Orixás (1985), de Almeida Prado (1943-2010), são utilizados maracas e guizos, que fazem parte da 'família' dos chocalhos. Radamés Gnattali (1906-1988) foi outro importante compositor brasileiro que utilizou os chocalhos. Dentre suas obras, podemos citar o Concerto Carioca no 1 (1951).

Os chocalhos não foram utilizados apenas em orquestras, mas também foram e ainda são muito utilizados nas músicas para grupo de percussão. Inúmeros são os compositores brasileiros que utilizaram esses instrumentos em suas obras, dentre os quais podemos destacar: Osvaldo Lacerda (1927-2011), que compôs Três estudos para percussão (1966) e Três miniaturas brasileiras (1974); Eduardo Escalante (1937), que, em 1976, compôs Série Sudestina; Brenno Blauth (1931-1993), que escreveu Antes e Depois (1976); Sergio Vasconcelos Correa (1934), que compôs Concertante (1969/70); Willy Correa de Oliveira (1938), que compôs Memos (1977) para sete percussionistas e soprano; Eduardo Seincman (1955), que escreveu Seres Imaginários (1997) para treze percussionistas; Raul do Valle (1936), que, em 1975, escreveu Cammiantes (Comme un Jeu de Couleurs); e Marlos Nobre (1939), que, em 1963, compôs Variações Rítmicas.

\subsection{Afoxé}

A palavra afoxé, de origem iorubá, pode ser traduzida como 'enunciação que faz (alguma coisa) acontecer', ‘a fala que faz', 'encantamento', 'palavra eficaz, operante' (RISÉRIO, 1981, p. 12). O termo afoxé denota a festa profano-religiosa celebrada por algumas nações africanas, a qual é manifestada através do ritmo Ijexá. No Brasil, esse ritmo pode ser conhecido como ‘candomblé de rua'. No entanto, afoxé, além dessa manifestação religiosa, também é o nome dado a um instrumento da família da percussão.

Segundo FRUNGILLO (2003, p. 5), afoxé é um instrumento feito geralmente de coco seco, com a superfície lixada. Nesse coco, é feito um furo onde é encaixado um 'cabo', que serve de apoio para a mão. O coco é envolvido por uma malha ou rede de pontos grandes fei- 
ta de arame com pequenas sementes ou esferas de madeira, plástico ou metal. Atualmente, é muito comum encontrarmos o afoxé 'moderno' ou industrializado, que é feito com o corpo de plástico e no qual as sementes podem ser substituídas por esferas de plástico ou metal.

César Guerra-Peixe (1914-1993), compositor brasileiro, que além de estudar a música clássica internacional e o dodecafonismo, estava muito voltado a cultura e a música erudita brasileira, em sua obra Museu da Inconfidência (1972), fez uso do afoxé entre outros instrumentos de percussão.

Outro compositor brasileiro renomado a utilizar o afoxé foi Almeida Prado (19432010) em sua obra Sinfonia dos Orixás (1985). Essa obra que teve sua estreia em 1985, executada pela Orquestra Sinfônica Municipal de Campinas sob a regência do maestro Benito Juarez.

Na música para grupo de percussão, também encontramos o afoxé presente em algumas obras, como em Variações Rítmicas (1963) e em Rhythmetron (1968), de Marlos Nobre (1939); em Baianá du dotô (1975) e em Série Sudestina (1976), de Eduardo Escalante (1937); em Le cru et le cuit (1993/94), de Jorge Antunes (1942); entre outras.

\subsection{Reco-reco}

Segundo FRUNGILLO (2003, p. 272), reco-reco é qualquer tipo de material em cuja superfície (ou parte dela) seja feita uma série de cortes transversais e paralelos bastante próximos, formando uma porção dentada. Nessa sequência de 'dentes' é esfregada uma baqueta ou vareta. Dentre os materiais mais utilizados, encontram-se o bambu ou a cabaça, mas o reco-reco também pode ainda ser feito de metal, de madeira e até mesmo de osso.

No Brasil, não podemos falar de reco-reco sem mencionar um dos maiores especialistas nesse instrumento, o paulista Carlos Stasi (1963), que desenvolveu pesquisa de mestrado e doutorado a respeito de reco-recos. Stasi pode ser considerado um dos maiores compositores de obras eruditas para percussão em todo o mundo, contando com centenas de composições para o instrumento. Apesar de numerosa, a imensa maioria de suas obras nunca foi gravada, nem sequer executada em apresentações públicas, principalmente por terceiros, e, se depender de Stasi, ainda é possível que essa situação continue assim por um longo tempo.

Para Stasi, os reco-recos estão entre os mais antigos instrumentos fabricados pelo homem (Idade da Pedra / Paleolítico: cerca de 15 mil anos atrás), tendo sido usados em todos os continentes, em diferentes épocas e culturas. Reco-reco é o terno utilizado genericamente no Brasil para denominar os instrumentos idiófonos raspadores como um todo (STASI, 2011, p. 19).

O reco-reco é regularmente usado na música popular brasileira, principalmente no samba, nos grupos de samba ou mesmo nas escolas de samba. Um personagem muito conhecido e que se destacou tocando o reco-reco de mola foi Antônio Carlos Bernardes Gomes (1941-1994), mais conhecido como Mussum, o mesmo Mussum humorista e integrante do grupo ‘Os Trabalhões’ com Renato Aragão (1935), Dedé Santana (Manfried Sant’Anna1936) e Zacarias (Mauro Faccio Gonçalves 1934-1990).

Na década de 1960, Mussum juntou-se aos amigos músicos para formar o grupo 'Os Sete Modernos', depois conhecido como 'Os Originais do Samba'. Em entrevista feita ao documentário Retratos Brasileiros no ano de 1998, dirigido por Sérgio Rossini no Canal Brasil, a grande sambista e cantora Alcione (1947) revela: "Nunca vi ninguém tocar reco-reco como o Mussum! Ninguém tinha aquele suingue, só ele...”. No mesmo documentário, o sambista e 
cantor Jorge Aragão (1949) completa: “...é agulha no palheiro achar uma pessoa com o mesmo suingue que ele fazia, que ele tinha naquele reco-reco...”.

Outro nome que se destaca em meio ao samba, só que tocando o reco-reco de madeira, é o músico José Belmiro Lima (1939), mais conhecido como Mestre Trambique. Foi fundador da escola de samba mirim Herdeiros da Vila, no bairro de Vila Isabel - RJ, onde leciona percussão, ensina jovens a tocar, a afinar e a se apresentar. Mestre Trambique já gravou mais de 60 músicas em 23 diferentes discos, fez parte da banda e gravação de CD e DVD de vários artistas, tais como Ney Matogrosso, João Nogueira, Cartola, Wilson das Neves, Wilson Moreira, Bezerra da Silva, e, ultimamente faz parte do Grupo Semente que acompanha a cantora Tereza Cristina.

O reco-reco fez e faz parte da música popular brasileira, e não está presente apenas nesse segmento musical (popular), mas também na música brasileira, seja ela popular ou erudita, integrando, por vezes, as orquestras sinfônicas. Prova disso é a inclusão desse instrumento no repertório composto por compositores nacionais mundialmente reconhecidos.

Alberto Nepomuceno (1864-1920), compositor brasileiro considerado, por muitos pesquisadores, como "pai” do nacionalismo na música erudita brasileira, pode ter sido o primeiro grande compositor a utilizar o reco-reco, inclusive, tendo utilizado este instrumento em Batuque (1888), quarta parte de sua Série Brasileira, que incluía ainda as seguintes partes: 1. Alvorada na serra (1892); 2. Intermédio (1891); 3. A sesta na rede (1896).

Villa-Lobos, outro grande compositor brasileiro, também fez uso do reco-reco em suas obras, a citar: Uirapuru (1917), Nonetto (1923), Choros no 6 (1926), Choros no 9 (1929), Choros no 10 (1926). Em 1939, compôs uma cantata profana baseada em lendas de índios do Amazonas, com os coros sinfônico e infantil, intitulada Mandú-Çarará. Provavelmente, $O$ Trenzinho do Caipira, que faz parte da sua obra Bachianas Brasileiras no 2 (1930) é um dos trechos mais famosos, onde, junto com outros instrumentos de percussão como ganzá, chocalhos, pandeiro e matraca, o reco-reco ganha destaque por "imitar" o movimento de uma locomotiva.

A primeira obra brasileira escrita para grupo de percussão erudita foi coincidentemente, a primeira a utilizar o reco-reco: Estudo para Instrumentos de Percussão. Estreada em 1979, essa obra foi composta em 1953 por Camargo Guarnieri, e requer oito percussionistas para a execução. A obra foi escrita para tímpanos, caixa-clara, tambor militar, bombo, pratos à 2, pandeiro, triângulo e reco-reco (HASHIMOTO, 2003, p. 69).

Podemos afirmar que o compositor brasileiro que mais utilizou o reco-reco em suas composições foi Carlos Stasi. A grande diferença entre as obras de Stasi e as outras aqui já citadas é que, para Stasi, o reco-reco é praticamente o instrumento solista, não serve apenas como acompanhamento rítmico para outros instrumentos. Para Stasi, o reco-reco é a própria música.

Entre as centenas de obras de Stasi compostas para percussão que utilizam o reco-reco, podemos citar Estudos para Reco-reco (1983) para 1 percussionista, 33 Samra Zabobra (1987) para mínimo de 4 percussionistas, Para Raspadores (1987), Haneman (1987) para 2 percussionistas, Barú (1988) para 2 percussionistas, Estudos para Mão Esquerda (1988) para 2 percussionistas, entre outras.

\subsection{Agogô}

Frungillo afirma que o agogô é de origem africana, mas difundiu-se muito na música brasileira, sendo um instrumento essencial no maracatu, afoxé e no samba. Constituído 
de duas, três ou quatro 'campânulas' de metal unidas por uma haste, pode ser tocado com vareta de ferro ou de madeira. Também pode ser conhecido como agoguê, gonguê, 'ferro', ngongui. Afirma ainda que podemos encontrar, de maneira mais rara, agogôs de madeira, coco, cabaça, cuja construção se assemelha à do agogô de metal.

O agogô é um instrumento muito utilizado na música popular brasileira, capoeira, maracatu, forró, samba e outros, mas também teve seu uso na música erudita brasileira. Camargo Guarnieri utilizou o instrumento em 1937, na sua obra Flor de Tremembé para quinze instrumentos solistas (flauta, clarineta, saxofone alto, fagote, trompa, trompete, trombone, harpa, piano, cavaquinho, quarteto de cordas) e percussão (chocalho, reco-reco, cuíca, agogô). Essa obra chamou a atenção da crítica da época por sua formação nada tradicional.

Radamés Gnattali compôs em 1976 sua cantata umbandista para orquestra, coro e narrador, sobre texto de Alberto Simões da Silva (1898-1986), conhecido como Bororó, intitulada Maria Jesus dos Anjos. Dentre vários instrumentos de percussão utilizados por Gnattali, o agogô faz-se presente nessa obra.

Ainda podemos destacar de Almeida Prado a Sinfonia dos Orixás (1984-85), que conta com vários instrumentos de percussão como tímpanos, vibrafone, marimba, bumbo, atabaques, afoxés, chocalhos, entre outros. Uma curiosidade é que, nessa obra, são utilizados 6 agogôs de duas campânulas distribuídos entre seis dos sete percussionistas necessários para sua execução.

Na música erudita para grupo de percussão, o agogô também foi muito utilizado e passou a integrar as músicas de grandes compositores brasileiros. Destaco algumas obras desses grandes compositores: Buquera (1973) e Guaraqueçaba (1976), de Breno Blauth (1931); Forró do Eu Sozinho (1972), de Sergio Vasconcelos Corrêa (1934); Invenção 1 (1973), Baianá du Dotô (1975) e Série Sudestina (1976), de Eduardo Escalante (1937); Três Estudos para Percussão (1966), Ponto de Iemanjá (1968) e Três Miniaturas Brasileiras (1974), de Osvaldo Lacerda (1927-2011); Seres Imaginários (1997), de Eduardo Seincman (1955); e Variações Rítmicas (1963), de Marlos Nobre.

\subsection{Pandeiro}

Pequeno tambor com platinelas (pequenos discos de metal) difundido praticamente em todo o mundo, o pandeiro possui uma pele (membrana) presa ao casco (corpo do instrumento), que, por sua vez, pode ser feito de madeira ou de metal, podendo ser encontrado também de bambu e de cabaça. Ao redor do mundo, os pandeiros são tipicamente utilizados em inúmeras danças populares. No Brasil seu uso tem sido destacado na música popular.

O pandeiro chegou ao Brasil, provavelmente, por meio da colonização portuguesa, misturando suas tradições ibéricas com os ritmos africanos vindos de países como Kongo, Angola, Moçambique, entre outros, ampliando as possibilidades de exploração rítmica até então não exploradas no instrumento.

No Brasil, podemos destacar dois tipos de pandeiros bastante comuns e, provavelmente, os mais usados. São eles o pandeiro feito com pele de nylon (tipo de plástico) e o pandeiro feito com pele de couro. Atualmente, o mais usado em diversos estilos na música popular brasileira é o pandeiro com pele de couro que mede, aproximadamente, 10" (dez polegadas), composto por um aro de madeira e uma fileira de platinelas. Outro pandeiro, também composto por um aro de madeira ou de plástico, e com uma fileira de platinelas, possui geralmente 12” (doze polegadas). Sua pele é de plástico ou material sintético similar. 
Também é possível encontrar pandeiros de nylon com 10” (dez polegadas). Ambos necessitam de pequenas garras de metal usadas para fixar a pele ao aro, de modo que sua tensão seja controlada. O pandeiro de nylon, por vezes, pode conter as garras agrupadas em pares, para fixar a pele ao aro com maior eficiência. Para GIANESELLA (2009, p. 160), o tamanho e a fácil portabilidade do instrumento, em comparação à maioria dos instrumentos de percussão, podem ter sido uns dos fatores que contribuíram para a difusão do pandeiro na cultura brasileira.

Podemos destacar algumas obras brasileiras para grupo de percussão erudita, a citar: Série sudestina (1976), de Eduardo Escalante; Impressões de um ensaio geral (1997), de Edmundo Villani Côrtes; Divertimento para pandeiro estilo brasileiro (1992), de Luiz D’anunciação; Cá entre nóis (2004), para quatro pandeiros sinfônicos e quatro pandeiros brasileiros, de Xico Abreu.

Na obra Cá entre nóis, o compositor utiliza quatro pandeiros sinfônicos, explorando os timbres das platinelas e da pele. No decorrer da obra, os percussionistas trocam os pandeiros sinfônicos por pandeiros brasileiros, usando três pandeiros de choro (com pele de couro) e um pandeiro com pele de nylon. Nos pandeiros brasileiros, são explorados seus diversos timbres e ritmos. Cá entre nóis foi gravada pelo Grupo DURUM Percussão Brasil no cd Dimensões em 2008.

\subsection{Tamborim}

O tamborim é um tambor pequeno com cerca de 6" de diâmetro. Os mais modernos têm o com corpo de metal, porém os antigos tinham o corpo de madeira. Em uma de suas extremidades, há uma pele de couro ou sintética, mais comum nos dias de hoje. Esse instrumento é segurado com uma das mãos e tocado por uma baqueta com a outra. Ele pode ser considerado um dos instrumentos mais característicos do samba e é praticamente indispensável nas escolas de samba.

Foi nas Escolas de Samba onde o tamborim se fez conhecido. A primeira Escola de Samba a utilizar o tamborim foi a Deixa Falar, fundada pelos sambistas Ismael Silva (19051978), Alcebíades Barcelos, o Bide (1902-1975), seu irmão Mano Rubem (Rubem Barcelos 1904-1927) e Armando Marçal. Essa Escola contribuiu muito para o carnaval e, automaticamente, para a música popular brasileira, influenciando alguns importantes compositores da época.

O tamborim também foi usado na música erudita brasileira. Villa-Lobos fez uso do instrumento em algumas de suas músicas como o Poema Sinfônico Uirapurú (1917), Rudepoema (1926), Choros No 6 (1926), Choros No 9 (1929) e Rogozijo de uma Raça (1937) para coro e percussão. Outra importante obra do repertório brasileiro em que podemos perceber o tamborim como destaque é o Concerto Carioca No 1 (1950/51), de Radamés Gnattali, em cujo quarto movimento, chamado de Samba, o compositor utiliza seis percussionistas. Estes tocam o tamborim, agrupados em três pares, executando três linhas rítmicas diferentes. Além dos seis percussionistas que tocam o tamborim, ainda são necessários outros seis para tocar os outros instrumentos de percussão contidos na obra, formando um total de doze percussionistas (BARROS, 2015, p. 85 ).

Usado não só nas orquestras sinfônicas, o tamborim também passou a ser usado nos grupos de percussão eruditos brasileiros. O primeiro compositor brasileiro a usar o tamborim para esse tipo de formação foi Marlos Nobre, compondo Variações Rítmicas (1963). Até onde se tem notícias, essa foi a primeira obra brasileira para grupo de percussão a uti- 
lizar o tamborim. Também é possível citar outras obras como: Forró do eu sozinho (1972) e Potyrom (1976/78), de Sergio Vasconcelos Corrêa; Três Miniaturas brasileiras (1974), de Osvaldo Lacerda; Commiantes (1975), de Raul do Vale; Baianá du dotô (1975) e Série sudestina (1976), de Eduardo Escalante; Pratilheiros Catapimbásticos (1994), de Eduardo Guimarães Álvares; Promenade (1997), de Fernando Iazzetta; Impressões de um ensaio geral (1997), de Edmundo Villani Côrtes; Três bambas (2002) de Lucas Rosa; entre outras.

\subsection{Atabaque}

Os atabaques eram feitos de troncos de árvores escavados em formato cônico onde era colocada uma 'pele' na borda maior. Essa 'pele' poderia ser tensionada por cordas que eram amarradas ao 'corpo' do atabaque. Nos instrumentos industrializados, o corpo do atabaque, ou casco, tem sido feito com barras de madeiras pregadas e coladas, e a pele é fixada por meio de um aro. Faz parte do instrumental dos ritos do Candomblé, mas difundiu-se indistintamente em diversas manifestações folclóricas. As dimensões do atabaque determinam sua tessitura. Lé, rumpi e rum, do mais agudo ao mais grave.

No Candomblé, religião africana que cultua os orixás, deuses ou divindades que representam as forças da natureza, os atabaques são considerados instrumentos sagrados e são usados nas festas religiosas dos negros de origem Gege, Ketu e Angola. São utilizados exclusivamente nas dependências do terreiro ou altar, não podem ser tocados nas ruas e são preparados e encourados com couros dos animais que são oferecidos aos Orixás.

Os atabaques também passaram a ser utilizados na música erudita. Provavelmente, um dos primeiros compositores a introduzir esse instrumento nas obras orquestrais foi Villa-Lobos. Em suas obras o termo que se refere ao instrumento atabaque é o caxambú. Gianesella (2009), em sua tese, cita essa possível substituição que poderá ocorrer em umas das obras de Villa-Lobos.

O caxambú, por ser um tipo de atabaque de som grave, normalmente de confecção artesanal, pode ser substituído por um atabaque convencional, ou uma conga grave, mas lembrando que aqui e em outras obras de Villa-Lobos ele deve sempre ser tocado com a mão, buscando-se o som solto, para se obter a sonoridade característica do instrumento. (GIANESELLA, 2009, p. 145)

Partindo dessa afirmação, podemos destacar algumas das principais obras escritas por compositores brasileiros que utilizam o atabaque e/ou o caxambú.

Provavelmente, a primeira obra erudita do repertório nacional a utilizar o atabaque (caxambú) tenha sido Nonetto (1924), de Villa-Lobos, obra estreada em Paris, em 1924. Foi composta para flauta, oboé, clarinete, saxofone, fagote, celesta, harpa, piano e percussão. Na percussão, são usados os seguintes instrumentos: tímpanos, xilofone, tam-tam, caixa-clara, bumbo, pratos, chocalhos (metal e madeira), triângulo, reco-reco, pandeiros, puíta (cuíca) e caxambú.

Podemos encontrar o atabaque não só em Nonetto, mas também em outras obras de Villa-Lobos como: Choros No 10 (1926), que tem na percussão instrumentos como tímpanos, tambor tenor, caixa-clara, caxambú, bloco de madeira, reco- reco grande e pequeno, chocalhos de madeira e metal, 2 bumbos, tam-tam grande e gongo e duas puítas; Choros No 09 (1929), que utiliza tímpanos, tam-tam, bombo, triângulo, reco-reco, caxambú, tamborim de samba, tambor de língua (ou também chamado tambor de fenda), surdo, camisão, chocalhos de metal e de madeira. 
Outro importante compositor brasileiro de destaque que tem o atabaque em sua obra é Radamés Gnattali. Em 1964, compôs Maria Jesus dos Anjos, uma cantata umbandista para coro misto, narrador, orquestra, e percussão popular. Entre os instrumentos de percussão usados nessa obra, destacam-se os atabaques.

O compositor e pianista brasileiro, membro da Academia Brasileira de Música e considerado um dos maiores nomes da música erudita no Brasil, Almeida Prado também compôs uma obra em que o atabaque ganha um papel relevante dentro do repertório erudito nacional, a Sinfonia dos Orixás (1985).

A utilização dos atabaques, por compositores brasileiros, também se deu entre os grupos de percussão erudita. Nesse segmento de percussão erudita para grupos de percussão no Brasil, umas das primeiras obras, senão a primeira, a usar o atabaque foi Variações Rítmicas opus 15 (1963) de Marlos Nobre. Outra obra importante do mesmo compositor que faz uso dos atabaques é Rhythmetron (1968), escrita para 10 percussionistas.

Outro grande nome da música brasileira que também utilizou o atabaque em suas composições foi Osvaldo Lacerda, autor de Três estudos para percussão (1966), Hiroshima Meu Amor (1968) e Ponto de Iemanjá (1968).

Em 1975, o compositor Eduardo Escalante escreveu Baianá du dotô para 7 percussionistas. Em 1976, compôs Série Sudestina para teclados e 8 percussionistas. Sérgio Vasconcellos Correa (1934) compôs Potyrom (1978). Eduardo Seincman (1955), compositor e professor, compôs Seres Imaginarios (1997), escrita para 13 percussionistas.

\section{Considerações finais}

O presente artigo abordou parte da trajetória composicional de Marlos Nobre, dando destaque a obra Variações Rítmicas opus 15, que, segundo estudos, pode ter sido a primeira obra de repercussão nacional composta para piano e percussão. Tal obra fez-se importante principalmente por incluir instrumentos típicos da percussão popular brasileira dentro do repertório erudito brasileiro para grupo de percussão.

Neste artigo, foi traçado um panorama dos instrumentos de percussão utilizados por Nobre (cuíca aguda, chocalho de metal, afoxé, reco-reco, agogô, pandeiro, tamborim e três atabaques), bem como o uso dos mesmos por parte de outros compositores brasileiros já consagrados nacional e internacionalmente.

Deste modo, damos destaque ao pioneirismo de Nobre ao compor para a formação instrumental já mencionada (piano e grupo de percussão), compositor que mesclou instrumentos populares da percussão brasileira com linguagem erudita, dodecafônica e com características de serialismo.

\section{Referências}

BARROS, Vinicius. C. O uso do tamborim por Mestre Marçal: legado e estudo interpretativo. Dissertação de Mestrado. Instituto de Artes, 2015. Campinas: UNICAMP, 2015. 178 p.

CUNHA, Ednelma L. S. Aspectos de coerência motivica e estrutural no Nonetto de Heitor Villa-Lobos. Dissertação de Mestrado. Instituto de Artes da Universidade de Campinas, 2004. Campinas: UNICAMP, 2004. $161 \mathrm{p}$.

FRUNGILLO, Mario D. Dicionário de percussão. São Paulo. Editora UNESP. Imprensa Oficial do Estado, 2003. 424 p. 
GIANESELLA, Eduardo. F. Percussão orquestral brasileira: problemas editoriais e interpretativos. Tese de Doutorado. Departamento de Música da Escola de Comunicação e Artes da Universidade de São Paulo, 2009. São Paulo: USP, 2009. 237 p.

HASHIMOTO, Fernando A. A. Análise musical de Estudos para instrumentos de percussão, 1953, M. Camargo Guarnieri; primeira peça escrita somente para instrumentos de percussão no Brasil. Dissertação de Mestrado. Instituto de Artes da Universidade de Campinas, 2003. Campinas: UNICAMP, 2003. $144 \mathrm{p}$.

MARIZ, Vasco. História da Brasileira da música. 4. ed. Rio de Janeiro: Civilização Brasileira, 1994. $372 \mathrm{p}$.

RISÉRIO, Antônio. Carnaval ijexá; notas sobre afoxés e blocos do novo carnaval afrobaiano. Salvador: Corrupio, 1981. 156 p.

STASI, Carlos. O instrumento do diabo: música, imaginação e marginalidade. São Paulo: Unesp, 2012. $116 \mathrm{p}$.

Rodolfo Vilaggio Arilho - Mestre em Música na área de Performance Musical pela UNICAMP, Bacharel em Percussão pela UNESP e ex-integrante do Grupo PIAP. Atualmente é Doutorando em Performance Musical (instrumento Percussão) pela UNICAMP, é percussionista da Orquestra Sinfônica Municipal de Campinas e membro-fundador do Grupo DURUM Percussão Brasil.

Fernando Augusto de Almeida Hashimoto - Professor Livre Docente na Universidade Estadual de Campinas, onde é responsável pelo Laborátorio de Percussão do Instituto de Artes da UNICAMP e líder do Grupo de Pesquisa CNPq: Percussão Brasileira: estudo interpretativo, levantamento histórico e seu repetório. Bacharel e Mestre pela UNICAMP, possui doutorado pela The City University of New York. 